\title{
I listen and I believe, I see and I understand: a collective reflection approach to understanding children's learning experiences
}

Carmen Mohamed, Lecturer in Education, University of Leicester, 21. University Road, Leicester, LE1 7YB

First published on: 15 June 2011

The project on which this report is based set out to establish how exploring children's musicality might encourage adults to consider their engagement with the musical play and learning of children under the age of five. Through reflection and evaluation the participants became aware that they were challenging their own teaching style in response to the children's exploratory learning. This became the central focus for the practitioners involved as it changed their understanding of their own practice. This paper endeavours to share the findings pertaining to the reflection, collaboration and change process of participants involved in the research project. It also describes practitioner involvement in this programme as an effective example of encouraging non-academic practitioners to take part in educational research.

Keywords: musicality; collaborative reflection; early years; play and learning

\section{Introduction}

There is a growing body of evidence which suggests that music can help to build young people's self-esteem and motivation and can have a positive impact on communication and social skills (Reddy and Trevarthen 2004; Young 2003; Trevarthen and Malloch 2002). The belief that this may contribute to raising standards across the curriculum gave rise to the Department for Children, Schools and Families (DCSF) commissioning the investigation into Music Services provision in England (Hallam et al. 2007). The survey data discovered that although 22\% of Key Stage 2 children were involved in instrumental tuition, only $5 \%$ of children under the age of seven were. 
In line with the outcomes of the research evidence, the Association of British Orchestras (ABO) and Youth Music identified the fostering of music in Early Years Children's Centres as an area of priority. A national action research programme was commissioned from researchers at Exeter University by Youth Music and ABO. This was driven by Young and Evans in an attempt to increase both the numbers of early years practitioners skilled in using music to support children's learning and the number of musicians skilled at working with early years children. The national programme was to be made up of several localised cluster projects. These localised projects would follow the programme outline and provide data collected to researchers at Exeter University, who continue to evaluate all projects taking place nationally.

The original premise for the national programme was to establish the reform of music education provision in the early years. Young purports that in our current system 'music education, serving the conventions of Western art music, has mostly prioritised the acquisition of formal skills in individualised musical activity' (Young 2004, 9). Until recently this acquisition of formal skills in individualised activity mirrored accepted educational activity across our schools. However, early education in Britain has undergone a change in priorities underpinned by the research of Moyles (2002), Sylva et al. (2004), Siraj-Blatchford (2008), Nutbrown (2006) and others. This culminated in the Early Years Foundation Stage (EYFS 2008), a set of guiding principles for teaching the very young. There is now an expectation in Britain that children under the age of five will be encouraged to learn through exploration and investigation.

In accordance with current research into early education and building on the work of Trevarthen and Malloch (2002) and Young (2003), Youth Music's ambitious study sought to "promote an approach that puts the child at the heart of the experience and fosters respect for children's existing musicality' (Evans 2007, 8).

\section{The localised cluster project}

The focus of this paper is on one of the localised cluster projects set up under the auspices of the national programme. Similar projects funded across England have culminated in a framework of training and practice, 'Tuning into Children' (Evans 2007). Each 12-week local project must be designed from this framework of guidance materials. The project outlined here set out to discover whether using the framework to explore the musicality of children under the age of five might 
encourage adults to challenge expectations of how they engage with children's musical play and learning.

This recommended approach to early childhood music practice defines and advocates principles which enable participants to build their own project within agreed parameters. The structure promotes the EYFS principles with a mixture of childinitiated, adult-responsive and adult-led music activity favouring an approach based on musical playfulness. The children initiate the music making which is supported and extended by the intervention of the adults. It describes a learning process for the adults informed by observation, reflection and the collaboration between early years' practitioners and musicians, based on mutual learning and respect for each other's skills.

Three Children's Centres in very different localities were able to offer sessional groups for the project, as was one maintained nursery class. They will all be referred to as 'Centres' for the purpose of this article. In each of the four participating Centres two sessional groups ran the music project; in nursery-aged groups (3-4- year-olds); in carer and toddler groups (2-3-year-olds); or 'stay and play' for carers with very young babies (0-2-year-olds). Enthusiastic and highly skilled musicians were recruited to offer a range of instruments enabling the inclusion of live music as an essential part of the experience. The professional musicians worked alongside early years practitioners for one session a week.

The 'Tuning into Children' framework offers an approach which recognises the differing expertise held by early years practitioners and musicians. It advocates working collaboratively and in constant dialogue to create a shared practice celebrating children's existing musical skills and competency within a social setting.

\section{Researching the project}

A range of ways to collect information and share experiences was planned. Some of these were based on numerical data needed for the national researchers, such as how many children from a range of ages and backgrounds attended. Data collected for our own project interests were written narrative evidence. Children and adults were photographed and videoed to capture the essence of each group for the final collaborative reflection and evaluation of the project. Regular observations carried out by the participants throughout each session detailed children's interests and engagement in the activities offered. These included observation through engagement 
and participation with the children as well as a degree of non-participant observations by the participants. At the end of each session time was set aside for reflective discussion in order to identify what were perceived to be critical incidents to the research and to plan steps to develop and enhance the project. The information from observations formed the basis of the collaborative reflection and evaluation at the end of the session.

Two hundred and forty hours of video footage was taken at all Centres across the life of the project by an experienced school videographer. He knew the locality and attended the evaluation meetings so that he was informed of the aims and outcomes of the project. Decisions about involvement with children and parents were selected by musicians and early years practitioners either in reflective collaboration or in response to an event occurring at any given moment. The total video data were reviewed by the lead participants, and they selected portions for a 'shared experience' DVD in order to disseminate the project findings.

At each session the children participated with parental knowledge and consent.

Children under the age of three participated with their parent or carer. Over threes had a parent/carer or their pre-school qualified teacher involved in the planning and delivery of the session. Procedures for informed consent were set up as a requirement of involvement. The Children's Centre managers were responsible for obtaining permission and making the purpose of data collection and storage clear to parents and other participants. Where parents requested, there was no photography or video footage of themselves or their children as we could not guarantee anonymity. Measures taken to ensure confidentiality, privacy and data protection were outlined in the research project and shared with participating Children's Centre managers.

During the course of the project children were not interviewed, only observed in their interactions with the musical instruments and the games that were provided. The research focused on the adults' involvement and acceptance of the way children play and learn. Children were not directly being researched therefore power relations considered were within the adult group.

My experience as an early years' consultant was matched by an experienced music consultant to create the 'research team'. This partnership managed the overall project but was largely non-participant in the sessions. The research team led the design of the 12-week project providing training and support for the participants and creating the monitoring schedules for data collection. They carried out formal structured 
observations at the early and later stages of the project to note changes in adult and child behaviour and provided the systems and formats for collecting data and analysing findings. Ultimately the data were analysed and evaluated by the research team.

Each Centre had its own project team comprising four 'lead participants'. This included a music leader and a professional musician working in partnership with an early years' practitioner and a teacher. The music leader was a professional musician who had some knowledge of either the national project or of working with very young children. The teacher was encouraged to disseminate the practice to other members of Centre staff to sustain the benefits of the project. This team observed, reflected and collaborated to create the most effective sessions for the groups they worked with. The four lead participants from each team were involved in the original training session, the mid-point evaluation meeting and the final evaluation meeting. The early years practitioners and musicians kept collaborative journals (A3 scrap books) of sessional observations, evaluations and reflections which detailed: the impact of the project on their involvement with the children; the involvement of parents and other adults in the children's play; and the critical incidents of musicality and learning the children demonstrated. Time for reflection with parents was built into the end of each session so that everyone was encouraged to share new learning or exciting developments for themselves, the children or the team. This stimulus enabled us to see which particular techniques or sessions had a greater impact, or if giving extra time or using a different space influenced the children's engagement. All participants were aware of the purpose of collecting data and were willing to share their findings at the evaluation meetings.

\section{Project implementation}

The aims and principles of the 'Tuning into Children' framework were outlined at an introductory briefing session. Participants were given their own copy of the framework to encourage shared agreement of the principles and approach. This initial meeting of the lead participants included the sharing of current theories in child development and musicality which underpinned the programme. Several of Young's (2003) recommended musical learning activities and ideas for how the sessions might run were trialled. The singing, dancing and musical play included in the session created a real enthusiasm in all those taking part and helped the team to bond. 
Participants agreed that involvement in the project could make a difference to children's musical learning.

Acceptance of all the participants and their status within the setting was reliant on trust between project leaders, practitioners, parents and children. However, even with the high degree of enthusiasm demonstrated by the participants, for some of the early years' practitioners, working with professional musicians was remarked on as 'unnerving'. Equally the notion of child-initiated and adult responsive music activity was not familiar to the musicians as their expertise in instrumental tuition is more adult framed and time restricted. There was agreement between all parties that teaching strategies were to be responsive to children's interests; they would not direct the activities; they would share their expertise; and that they would support each other in their developing understanding of the project aims: The 'Tuning into Children' framework reflects a practice which centres on children's musical creativity and the essential relationship between child-initiated, adult-responsive and adult-framed music activity and the use of observation, documenting and reflection to inform this process (Evans 2007, 9).

This three-strand framework was developed for each of our sessions, starting with 'free exploration' (child-initiated) where the children were encouraged to use and explore the instruments freely. The intention was that the adults should observe without interference in the first instance. This experience encouraged the adults to relinquish control of the situation and learn from the way the children engaged in 'child-initiated' play and learning. This approach is aligned to the EYFS Principles and Practice Guidance which states that 'play underpins all development and learning for young children' $(2008,5)$. The guidance continues with an assertion that the role of the practitioner in observing and reflecting on children's spontaneous play is crucial to their development.

According to Young $(2004,9)$, in Britain 'the socio-musical skills of coordinating musical activity with others have not been given importance'. Imitating and responding to each other's musical play is central to the approach taken within this project. Adults were therefore encouraged to take part in 'responsive' play. They were to explore the instruments, play them in unconventional ways and copy how the children experienced them, imitating the children and developing 'musical conversations' (children and adults responding to each other's playing) through the instruments. 
This 'responsive' play was followed with an 'adult-framed' activity structured and often led by the early years practitioner. This was in the traditional style of everyone joining in a directed singing or movement activity. Meanwhile, the musicians played their instrument imitating the movement of particular children or following the mood of the group. They were all highly skilled and with varying ease learnt to let go of performing and instead follow the children's lead. The sessions always included these three elements of practice but the timing, position and range of activities were flexible in response to the children's interests. Musicians played inside and outside throughout the session, accompanying the singing, responding to dance, playing alongside, mirroring and creating a sense of awe, whilst remaining approachable and simply part of the children's play. Non-verbal communication was paramount and natural 'musical conversations' commonplace. This 'child-initiated-adult-responsive' method of teaching began to make sense to the participants the more comfortable they became with it.

Different rhythms, styles and beats were introduced from within the group and from musicians' experience of using music to help people to bond. Opportunities for movement and dance were built in along with time for singing together which was often introduced and led by the children. These activities encouraged the adults to participate in the way the children wanted to learn and removed the need for them to feel in control. In the pre-school groups where parents did not attend, these elements were placed towards the end of the session so that they could also join in, giving further emphasis to the importance of the social aspect of learning. As the Centres have ethnically and socially diverse communities, it was crucial to ensure the musicians developed confidence in songs, rhymes and action games from a range of cultures. It was also important not to impose songs and games but to start from what the group members wanted to share and to build upon the pleasure of sharing and the comfort of familiarity. This also allowed participants to utilise the children's prior skills and competencies, a key principle of early education. The project aims were not shared with the children. The agenda we offered to them was the freedom to explore the instruments in their play.

\section{Researching the project}

It was possible to assume that all involved parties shared a common frame of reference, as suggested by Drever (1995) since all had participated in the original 
training sessions and were following the same project framework. Through listening to and observing the musical activity and imitating the children's play, participants hoped to develop an understanding of how the children generated their own musical ideas. Observations were both participant and non-participant in order to record in detail how the children responded to activities and instruments; to each other and adults; and to the different structures offered in the learning environment. As Mayall (2001, 121) points out: Participant observations with children in the anthropological tradition include watching, listening, reflecting and engaging with children in conversation. The adult tries to enter the children's worlds of understanding and her own understanding thereby modifying her agenda through the research experience. The practitioners were attempting to understand how this child-initiated, adult responsive method of teaching would impact on children's engagement and learning. The recorded observations were reflected upon collaboratively at the end of each session, and critical incidents were analysed by the teams for project development purposes. In this way the teams also gained insight into the preferences of the children by monitoring their reactions to changes in session structure and the environment and responding accordingly. This type of collaborative relationship in research is what Blaise Ochsner refers to as 'reciprocity' (in MacNaughton 2001, 255). This term accurately describes our involvement in the process 'where the researched help with the decision making about the research' (ibid.). Participants were engaged in a 'collaborative relationship as participant observers and in the sharing of collective reflections' (ibid.).

The action research relied heavily on the perceptions and honesty of the respondents in both the semi-structured evaluation reports and their journals. The narrative approach was chosen to describe the personal transition based on a premise that the 'beliefs people have about themselves may be reflected in the stories that they tell themselves and others' (Korthagen 2004, 81). As was described in MacNaughton's 2001 study, each group member agreed to observe what was happening in their sessions, document this and then to share what they had learnt in the project evaluation meetings (MacNaughton et al. 2001). Participants were to use all the evidence they were collating to identify events which they found striking, useful, challenging or which raised questions. Lead participants were asked to provide this feedback in the form of a presentation to the rest of the Centre teams at the evaluation 
meetings. This feedback allowed us to gather views and perspectives from the participants about their personal journey.

It is generally believed that qualitative methods are more effective than quantitative methods if the aim is to find out what people feel, think and believe (Bragg 2007). However, the information collected needed to be quantifiable in order to state which responses were observed in the children with most regularity. The research team created guidance to clarify what to include in the journals, leaving them as open as possible to enable us to gather information we would not necessarily expect. Semistructured evaluation reports from each group were aligned to the project monitoring and evaluation framework. This allowed participants to collate their findings, relating them to the aims of the project and their own learning and development. The overriding question to frame the group evaluation summary was 'What are we learning about how we interact with children's musical experiences?'

The evaluation meetings at both the mid-point and the end of the project were structured to allow for differences within the groups and to follow areas of interest raised. This had the effect of creating a larger scale collaborative reflection. The impact of all groups listening to the reflective learning of each other triggered new thoughts and observations for their group. These project-wide reflective discussions allowed each team to discover similarities and differences within their Centre. They enabled us to pinpoint what was important to us as individuals, as teams and to the project aims.

By allowing the leaders and other participants to probe the reasoning behind responses in detail, we yielded thoughtful responses. It also brought up new issues that the leaders would otherwise not have been aware of. It is widely agreed that where researchers use experience and understanding to construct their theory, the data are likely to be coloured with the meanings and purpose of those people who are the source of information. However, these meetings were used to reflect retrospectively on what had happened in each of the projects and to plan the next step. According to Hughes $(2001,212)$, 'the action research cycle only progresses when you can critically reflect upon and criticise your findings, understandings and practices with others'. As we continually make sense of our circumstances we negotiate meanings with others. This process aims to create change by questioning taken for granted ways of understanding and doing things. This pattern of planning in action, observing, documenting, sharing and reflecting continued for the 12 weeks of each project. 
Cohen, Manion, and Morrison observed that 'in qualitative data validity might be addressed through the honesty, depth, richness and scope of the data achieved, the participants approached and the objectivity of the researcher' $(2000,105)$. Although our data are subjective and founded out of experience and thought, the feedback meetings were emotionally charged and offered quite personal accounts of the experiences of the practitioners and musicians. This led us to be confident of the impact of the project on the practice discussed.

\section{Summary of findings}

In line with the National Programme aim to instigate the reform of music education, this project originally set out to establish how exploring children's musicality might encourage adults to consider their engagement with the musical play and learning of children under the age of five. The national project offered a framework to scaffold the process by which participants would allow children to lead their own learning experiences. The framework encouraged participants to allow children the freedom to explore the instruments on offer and to observe their behaviour and interactions. Through observation and the collaborative reflection approach to change, participants discovered that the children were able to organise their play with instruments demonstrating musicality in a sociable and co-operative way.

During the evaluation meetings the project teams reported agreement that 12 weeks were necessary to build the project and consolidate ideas. In fact the collaborative journals identified that it was at the mid-point of the project that change in attitudes and assumptions began to change practice. All the way through participants were challenging their own and each other's attitudes to this new way of working with children. Some found it easy and enriching, others found the step too difficult at first and needed gentle coaxing. Many participants admitted in the journals that they found it difficult to change the focus of teaching from adult directed to sessions being designed and led by the children. Play and especially repetitive play can create a dilemma for adults working with very young children. They are uncertain when or how to intervene. This uncertainty is linked to the view of the child as a learner and the purpose of education and care facilities. However, as Trevarthen and Malloch purport: The most successful teachers of music follow the child's natural musicality and share his or her appetite to know more about living and moving. They do not 
simply instruct in the rational structures that have been invented to aid the skilled practices and preservation of music. (Trevarthen and Malloch 2002, 16)

Whilst this project was built around the music sessions, the principles and the structure adhere closely to early years principles and practice as outlined in the EYFS. Participants needed to create a distance from direct teaching. This allowed for observation of what the theoretical paradigms suggested children could and would do with musical instruments if left to explore independently. According to Reddy and Trevarthen $(2004,11)$, 'Our responses within engagement not only allow us to notice and to interpret specific behaviours of the infant but also to recognise and legitimise these behaviours'. Through a process of review and reflection it was established that children co-ordinated their play through communicative and expressive behaviours. However, what was emerging through the collaborative reflection process was evidence that the teaching practice of participants had been shifting because of their developing understanding built through observations of the children at play. Practitioners began to realise that engagement in the project was informing teaching and learning across all learning activities in the Centres.

It became apparent that the 'Tuning into Children' framework had scaffolded the transition in approach, and the energy and excitement of play which was encouraged by the music leaders broke down barriers quickly. It was reported that this degree of control in the process of collaborating in change, rather than being told in training or reading about new developments in early education, supported the practitioners through the sometimes painful barrier of change in their practice. In effect, using the framework liberated the practitioners to concern themselves with observing, reflecting and evaluating in order to create a more powerful learning environment for all, ultimately creating practitioners who were more 'confident, flexible andautonomous' (Hopkins 2008, 39).

\section{Re-examining the evidence}

Having spent many years delivering training for early years practitioners, this impact on practice as a result of involvement in this project was of great interest to me. The acknowledgement of participants that they finally understood the value of child initiated learning and adult-responsive teaching and were changing their practice accordingly was a real breakthrough in terms of training and development. As a result of this outcome I went back to the original data to ascertain whether there was any 
clear evidence that the emphasis on observation, along with the collaborative reflection approach taken for this project, had supported the practitioners in establishing a clear understanding of what exploratory learning or play meant for the young children in their care. This entailed scrutinising notes from the collaborative journals and the video evidence from a range of sessions across the project. Collaborative journals evidenced that it was becoming increasingly clear to the participants that children are generally not given enough space or time to find things out for themselves. Many recorded the observable differences in children's behaviour; the depth of exploration, the absorption and concentration when left to explore without adult intervention. 'Whatever form of communication is used, children need space and time to respond and to know that the practitioner is giving full attention and encouragement to their thinking' (EYFS 2008, 2.3). This principle of early years practice became increasingly evident in the journals as the participant became more comfortable to allow the children to lead the sessions. The participants claimed to be so inspired by the children's innate musicality that the essential focus of their role changed to observing how children interacted with the environment, thus enabling them, through the collaborative reflection process, to provide the most suitable climate for the children to develop and learn.

The documented observations and video evidence showed the children as 'social actors, not as passive participants' (Bragg 2007, 46), which, as Bragg found, had implications particularly in how 'power relations between adults and children were conceived and experienced' (ibid.). Change in the children's behaviour was recorded over the time of the project; in the beginning the children appeared nervous and suspicious of the adults allowing them to take charge of the sessions. During an initial observation by one of the researchers, children were noted to be watching adult reactions after each noise or movement. However, once they realised that no one was going to take back control they became much more comfortable and confident. From the minutes of the mid project monitoring and evaluation meeting it was evident that sharing each team's experiences resulted in participants collaboratively accepting that the adults involved gradually became more responsive in their interactions with the children. By the third week teams stated that the adults had begun to get the idea of not interfering in the music making. They would follow more and imitate rather than lead. This led to the conclusion that through observation and collaborative 
reflection participants were beginning to understand and translate the rhetoric of the principles of early education into reality.

Video evidence of groups with parental involvement demonstrated similar changes at the beginning of the project. Many parents were observed to simply hand the children instruments and expect them to take part. In the early sessions some children were at a loss. The practitioners suggested in the evaluation journals that the children needed to see their parent playing. Occasionally parents needed encouragement to let their children explore on their own, to not interfere but wait for an invitation to join in the music play.

One of the strengths of this project was the different backgrounds we all came to the project from. Our professional practices enabled us to guard against making hasty judgements because our interpretation had to be shared and evaluated by a range of practitioners. Its value was heuristic in that it helped participants to think for themselves. All came to value highly the collaborative learning experience.

\section{Exploring implications}

As an educational consultant I have delivered many training sessions on the current theories of children's developmental learning, which practitioners attempted with varying degrees of success to develop in their own settings. However, within this project the emotional impact and personal reactions to challenging assumptions and practice were readily shared. This powerful research project went further than any reading or training to change practice within these early years' settings. Participants were empowered through collaborative reflection to create a less adult-directed, adultperceived reality in which children were encouraged to explore freely.

Hopkins (2008, ix) observes that 'as we pursue an increasingly ambitious educational reform agenda it is vital that we take the opportunity to create a discourse around teaching and learning in our schools and communities'. The collective reflection approach empowered participants to critically review the experience for the child and interpret their needs as sessions were observed and evaluated. With the recent development in the early years curriculum frameworks, the structure of learning through play has become more clearly defined. Although the introduction of new methods of teaching has been well funded, this project indicates how it is not in the telling but in the reflection on observations of children that practitioners can begin to understand what exploratory learning is. Bennett, Wood, and Rogers $(1997,73)$ 
observed that teachers' intentions were not always well matched or appropriate and that they set up play activities which were accessed in a different way to their intentions by the children. If this was observed of the 'adult framed' activities during this project, the subsequent reflective discussion would analyse and interpret the findings in order to provide a more meaningful experience to the children at the next session. The practitioners were responsive to the children's needs rather than the children responding to the practitioner expectations.

The research project is likely to be published by the Exeter team as part of the national programme. However, it is important to practitioner research to publish the impact of their engagement in small-scale, well-designed projects which effect teaching strategies without requiring non-academic participants to publish their findings. There is currently a drive in British education to develop research by practitioners; involvement in this study demonstrated to participants how complex this is. Many of the 'Creative Partnership Projects' (2007) (established by The Arts Council to develop projects between schools and creative organisations or individuals) were built around the same action research principles. However, they required participants to create their own project and written evaluation. For this project, having a research team to scaffold the process was effective in creating a culture of inquiry, releasing participants from the detail of setting up and evaluating the project. As Campbell, McNamara, and Gilroy suggest $(2004,26)$, 'the role of higher education personnel in teacher research is a vital and a key one providing support for research through partnership'. The action research itself empowered the participants to be in control of their own professional development but the collaborative reflections provided a clear structure for discussion and eased the process of change and understanding. Most projects such as this would require a written account by the participants. In this case, reporting the data was left to professional academics.

The impact of the project and the training for early years' professionals, music leaders, musicians and project leaders was stated in feedback to be 'profound'. Every person involved in the project shared what they had learnt about the musical capability of young children and how as professionals they now relate to them in play. Many said that it had changed their teaching style across their work and as observers. The research team recognised the professional change and growth of self esteem in many practitioners. It was not enough to make sense of how people interpret 
children's musicality; it became crucial to change the attitudes and practice of the adults involved in the education of young children.

This change in approach to children's learning will be the most sustainable impact of the project and have an effect on many children both in their music learning and other areas of their learning and development. In this way we can ensure that "through freely chosen exploration, supported by sensitive, knowledgeable adults, young children learn how to learn' (Evans 2007, 22).

The early years' practitioners demonstrated increased confidence in their own musicality and the musicians were more comfortable with child-initiated learning. Most importantly those participating in the study re-evaluated the adults' role in teaching and learning. All believed in the pedagogical approach of exploratory learning for young children. All listened to the theoretical research which had underpinned the development of the programme but it was in the shared observations and collaborative reflections on the responses of the children to this level of freedom in their learning that participants began to fully understand its value in early education. This project has had a dramatic impact on how these significant adults communicate with young children in their play and learning in our local Centres. 


\section{References}

Bennett, N., E. Wood, and S. Rogers. 1997. Teaching through play: Teachers' thinking and classroom practice. Buckingham: Open University Press.

Blaise Ochsner, M. 2001. Developing reciprocity in a multi-method small-scale. In Doing early childhood research: International perspectives on theory and practice, ed. G. MacNaughton,

S.A. Rolfe and I. Siraj-Blatchford, 254-63. Buckingham: Open University Press. Bragg, S. 2007. Consulting young people: A review of the literature. 1st ed. A report for Creative Partnerships. London: Open University Arts Council.

Campbell, A., O. McNamara, and P. Gilroy. 2004. Practitioner research and professional development in education. London: Paul Chapman Publishing. Cohen, L., L. Manion, and K. Morrison. 2000. Research methods in education. London:Routledge Falmer.

Drever, E. 1995. Using semi-structured interviews in small scale research: A teacher's guide. Glasgow: Scottish Council for Research in Education.

Early Years Foundation Stage. 2008. Setting the standards for learning, development and care for children from birth to five. London: DCSF publications.

Evans, N. 2007. Tuning in to Children: A training handbook to deepen early years practitioners' and musicians' understanding of young children and their music making. London: Youth Music.

Hallam, S., A. Creech, L. Rogers, and I. Papageorgi. 2007. Local Authority music services provision for Key Stages 1 and 2. Research report number DCSF RR014. London:Institute of Education, University of London.

Hopkins, D. 2008. A teacher's guide to classroom research. 4th ed. Berkshire: Open University Press.

Hughes, P. 2001. Paradigms, method and knowledge. In Doing early childhood research: International perspectives on theory and practice. ed. G. MacNaughton, S.A. Rolfe and I. Siraj-Blatchford, 31-55. Buckingham: Open University Press. Korthagen, F. 2004. In search of the essence of a good teacher. Journal of Education for Teaching 21, 333-45.

MacNaughton, G., S.A. Rolfe, and I. Siraj-Blatchford, eds. 2001. Doing early childhood research: International perspectives on theory and practice. Buckingham: Open University Press. 
Mayall, B. 2002. Conversations with children; working with generational issues. In Research with children: Perspectives and practices, ed. P. Christensen, and A. James, 120-35. London: Falmer Press.

Moyles, J. 2001. Just playing? The role and status of play in early childhood education. Milton Keynes: Open University Press, 120-35. London: Falmer Press. Nutbrown, C. 2006. Threads of thinking: Young children learning and the role of early education. London: Paul Chapman.

Reddy, V., and C. Trevarthen. 2002. What we learn about babies from engaging with their emotions. Zero to Three 24, no. 3: 9-15.

Siraj-Blatchford, I. 2008. Understanding the relationship between curriculum, pedagogy and progression in learning in early childhood in Hong Kong. Journal of Early Childhood Education 7, no. 2: 3-13.

Sylva, K., E. Melhuish, P. Sammons, I. Siraj-Blatchford, and B. Taggart. 2004. The effective provision of pre-school education (EPPE) Project: Final Report. London: DfES.

Trevarthen, C., and S. Malloch. 2002. Musicality and music before three: Human vitality and invention shared with pride. Zero to Three 23, no. 1: 10-8. Young, S. 2003. Music with the under-fours. London and New York: Routledge Falmer.

Young, S. 2004. Collaboration between three- and four-year-olds in self initiated play with instruments. Proceedings of the 8th International Conference on Music Perception and Cognition, in Evanston, IL. 